\title{
A NOVEL APPROACH REVEALING THE EFFECT OF A COLLAGENOUS MEMBRANE ON OSTEOCONDUCTION IN MAXILLARY SINUS FLOOR ELEVATION WITH $\beta$-TRICALCIUM PHOSPHATE
}

\author{
Engelbert A.J.M. Schulten ${ }^{1, \S}$, Henk-Jan Prins ${ }^{1,2, \S}$, Janice R. Overman ${ }^{1,2}$, Marco N. Helder $^{3}$, \\ Christiaan M. ten Bruggenkate ${ }^{1,4}$ and Jenneke Klein-Nulend, ${ }^{2, *}$
}

\author{
${ }^{1}$ Department of Oral and Maxillofacial Surgery, VU University Medical Centre / ACTA, Research Institute MOVE, \\ Amsterdam, The Netherlands. \\ ${ }^{2}$ Department of Oral Cell Biology, Academic Centre for Dentistry Amsterdam, University of Amsterdam and VU \\ University Amsterdam, Research Institute MOVE, Amsterdam, The Netherlands. \\ ${ }^{3}$ Department of Orthopaedic Surgery, VU University Medical Centre, Research Institute MOVE, Amsterdam, \\ The Netherlands. \\ ${ }^{4}$ Department of Oral and Maxillofacial Surgery, Rijnland Hospital, Leiderdorp, The Netherlands.
}

\$Shared first authorship

\begin{abstract}
Calcium phosphates are used in maxillary sinus floor elevation (MSFE) procedures to increase bone height prior to dental implant placement. Whether a collagenous barrier membrane coverage of the lateral window affects bone formation within a bone substitute augmentation is currently an important matter of debate, since its benefit has not been irrefutably proven. Therefore, in this clinical study twelve patients underwent an MSFE procedure with $\beta$-tricalcium phosphate $(\beta-\mathrm{TCP})$. The lateral window was either left uncovered, or covered with a resorbable collagenous barrier membrane. After a 6-months healing period, bone biopsies were retrieved during implant placement. Consecutive $1 \mathrm{~mm}$ regions of interest of these biopsies were assessed for bone formation, resorption parameters, as well as bone architecture using histology, histomorphometry and micro-computed tomography. Comparable outcomes between the groups with and without membrane were observed regarding osteoconduction rate, bone and graft volume, osteoclast number and structural parameters of newly formed bone per region of interest. However, osteoid volume in grafted maxillary sinus floors without membrane was significantly higher than with membrane. In conclusion, our results - obtained with a novel method employed using $1 \mathrm{~mm}$ regions of interest - demonstrate that the clinical application of a bioresorbable collagenous barrier membrane covering the lateral window, after an MSFE procedure with $\beta$-TCP, was not beneficial for bone regeneration and even decreased osteoid production which might lead to diminished bone formation in the long run.
\end{abstract}

Keywords: Maxillary sinus floor elevation, collagenous barrier membrane, histomorphometry, micro-computed tomography, calcium phosphate, osteoconduction, bone formation, bone regeneration, bone architecture, bone resorption.

*Address for correspondence:

Jenneke Klein-Nulend, $\mathrm{PhD}$

Department of Oral Cell Biology,

ACTA-VU University Amsterdam,

Research Institute MOVE,

Gustav Mahlerlaan 3004,
1081 LA Amsterdam, The Netherlands,

Telephone Number: +31205980881 FAX Number: +31205980333 E-mail: j.kleinnulend@acta.nl

\section{Introduction}

Maxillary sinus floor elevation (MSFE) is a widely accepted and routinely used pre-implant surgical procedure to increase bone height in the posterior maxilla (Tatum, 1986; Zijderveld et al., 2009). MSFE enables dental implant placement and provides a stable basis for these dental implants. For bone reconstruction in the oral and maxillofacial region autologous bone is still the "gold standard" as grafting material. These bone grafts can be harvested from the iliac crest (Sindet-Pedersen and Enemark, 1990; Thorwarth et al., 2005), calvarium (Iturriaga and Ruiz, 2004), tibia (Jakse et al., 2001), rib (Borstlap et al., 1990) or intraoral donor sites such as the maxillary tuberosity, the retromolar area of the mandible (Thorwarth et al., 2005; Becktor et al., 2008) or chin (Borstlap et al., 1990). Autologous bone grafts have excellent osteoinductive, osteoconductive, and osteogenic properties (Oppenheimer et al., 2008). However, the use of autologous bone has also disadvantages, such as limited graft availability (Springfield, 1996), risk of infection (Arrington et al., 1996), the chance of morbidity at the donor site (Kalk et al., 1996; Raghoebar et al., 2001), including pelvic instability (Chan et al., 2001) and sensitivity disturbances (Beirne et al., 1996; Nwoku et al., 2005; Raghoebar et al., 2007). Finally, the autologous bone grafts have an unpredictable resorption rate (Burchardt, 1983). To overcome these disadvantages and to improve the overall patient's comfort, there is a continuous search for alternative treatments.

A variety of allogenic, xenogenic, and alloplastic bone grafting materials or combinations have been used as an alternative for autologous bone grafts in MSFE procedures (Farré-Guasch et al., 2012). Recently a meta-analysis demonstrated that $\beta$-tricalcium phosphate $(\beta-\mathrm{TCP})$ is the best alternative for autologous bone with regard to osteogenic potential (Klijn et al., 2010). The major advantages of the use of synthetic grafting materials are the 
Table 1. Data of patients treated with or without collagenous barrier membrane.

\begin{tabular}{|l|c|c|c|}
\hline Gender & Age & Collagenous barrier membrane & Implant position \\
\hline Male & 68 & no & 26 \\
\hline Female & 40 & no & 26 \\
\hline Male & 73 & no & 17 \\
\hline Male & 62 & no & 25 \\
\hline Male & 36 & no & 16 \\
\hline Male & 65 & no & 25 \\
\hline Female & 44 & yes & 26 \\
\hline Male & 57 & yes & 26 \\
\hline Female & 56 & yes & 15 \\
\hline Female & 66 & yes & 15 \\
\hline Female & 63 & yes & 16 \\
\hline Male & 53 & yes & 26 \\
\hline
\end{tabular}

Twelve patients (gender, age in years) who required a maxillary sinus floor elevation (MSFE) were treated either with $\beta$-TCP $\operatorname{Ceros}^{\circledR}>0.7 \mathrm{~mm}$ only, or with $\beta$-TCP $\operatorname{Ceros}^{\circledR}>0.7 \mathrm{~mm}$ in combination with a collagenous barrier membrane covering the lateral window. The Fédération Dentaire Internationale (FDI) system was used for the dental implant position.

reproducible production in unlimited quantities enabling the use as off-the-shelf products, and the absence of disease transmission risk. Calcium phosphate ceramics are very similar to the inorganic components of natural bone and therefore highly biocompatible.

The use of a membrane covering the lateral window of the maxillary sinus was suggested to be considered for all MSFE procedures (Tarnow et al., 2000). Moreover, a systematic review concluded that the use of a barrier membrane increases the survival rate of endosseous dental implants in the grafted maxillary sinus (Wallace and Froum, 2003). A resorbable collagenous barrier membrane has a bilayer structure with a porous surface (facing the bone) allowing the ingrowth of bone forming cells, and a dense surface (facing the soft tissue) preventing the ingrowth of fibrous soft tissue into the graft-filled area of the sinus. The use of barrier membranes for guided bone regeneration is not limited to the MSFE procedure, but is also used in restoration of large bone defects (Dimitriou et al., 2012). The collagen is resorbed within 4 months in bone cavities in animals (Owens and Yukna, 2001). The use of $\beta$-TCP in the MSFE procedure has been reported (Szabo et al., 2005; Zijderveld et al., 2005; Suba et al., 2006; Simunek et al., 2008). However, the effect of a collagenous barrier membrane to cover the lateral window on bone formation after an MSFE procedure with $\beta$-TCP has not been reported. Moreover, the reported percentages of bone volume in the grafted maxillary sinus floor are highly variable, since the residual maxillary sinus floor height and the spatial distribution of the newly formed bone throughout the grafted maxillary sinus were not taken into account. Evidently, a higher percentage of residual bone volume strongly influences the total bone volume percentage, which then does not represent an accurate measurement of the amount of newly formed bone as a result of the grafting. In this study, we attempted to tackle this problem by dividing the biopsies in consecutive socalled regions of interest (ROI) of $1 \mathrm{~mm}$ length.

Therefore, the purpose of this study was to evaluate the effect of using a collagenous membrane covering the lateral window in MSFE with $\beta$-TCP on bone formation and resorption parameters as well as bone structure by combining clinical data, radiological data as well as histomorphometrical and micro-CT data obtained using our novel approach for determination of osteoconduction in bone regeneration.

\section{Materials and Methods}

\section{Patient selection}

Twelve patients, who were partially edentulous in the posterior maxilla and requiring dental implant(s) for dental rehabilitation, were included in this study. Since all patients had insufficient maxillary bone height, MSFE procedures were performed as described previously (Tatum, 1986). The vertical alveolar bone height before MSFE was $\leq 7 \mathrm{~mm}$ in the posterior maxilla, but at least $4 \mathrm{~mm}$ at the dental implant positions. The mean age of the patients was 57 years, ranging from 36 to 73 years (without membrane: $57 \pm 15$ years; with membrane: $57 \pm 8$ years) (Table 1 ). This study was conducted with the approval of the local medical ethical committee, and all patients signed a written informed-consent before participation in the study. All patients were non-smokers or smoked $<10$ cigarettes per day. Patients with systemic diseases, drug abuse, and/or 


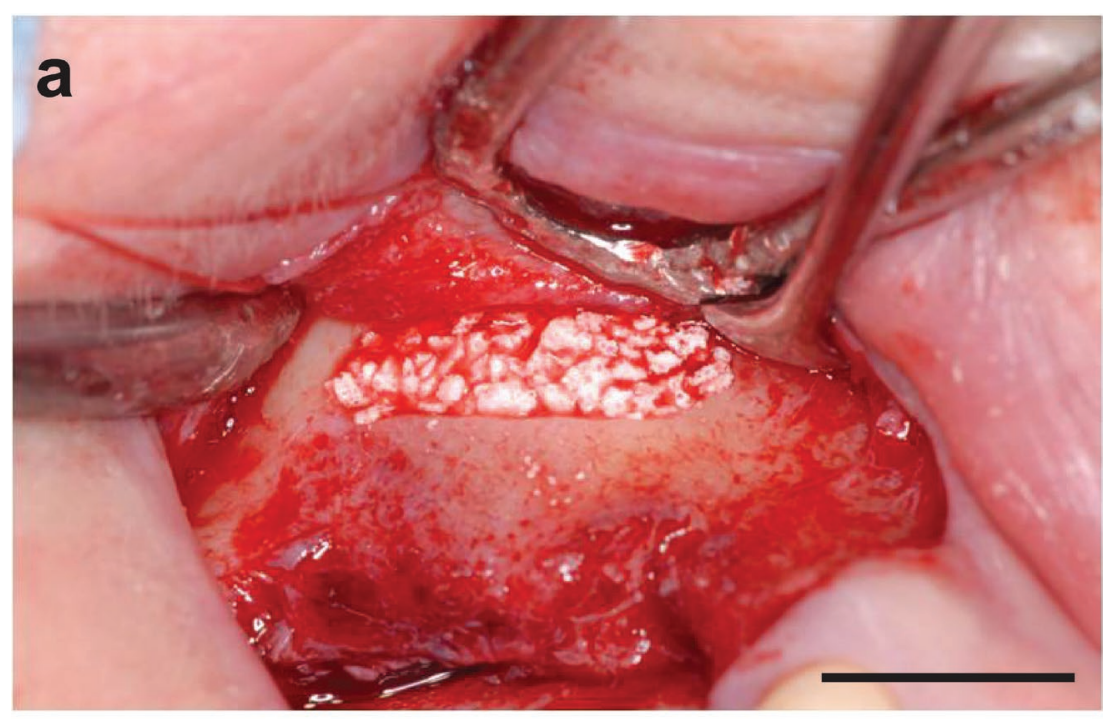

Fig. 1. Clinical photographs of a maxillary sinus floor filled with $\beta$-TCP with or without a collagenous barrier membrane covering the lateral window. (a) Clinical photograph showing the open space created within the maxillary sinus between the top-hinge trap door and the maxillary sinus floor, which is filled with $100 \% \operatorname{Ceros}^{\circledR} \beta$-TCP granules. The lateral window was left uncovered. (b) Maxillary sinus floor filled with $\operatorname{Ceros}^{\circledR} \beta$-TCP granules and a resorbable collagenous barrier membrane covering the lateral window. Scale bars represent $1 \mathrm{~cm}$.

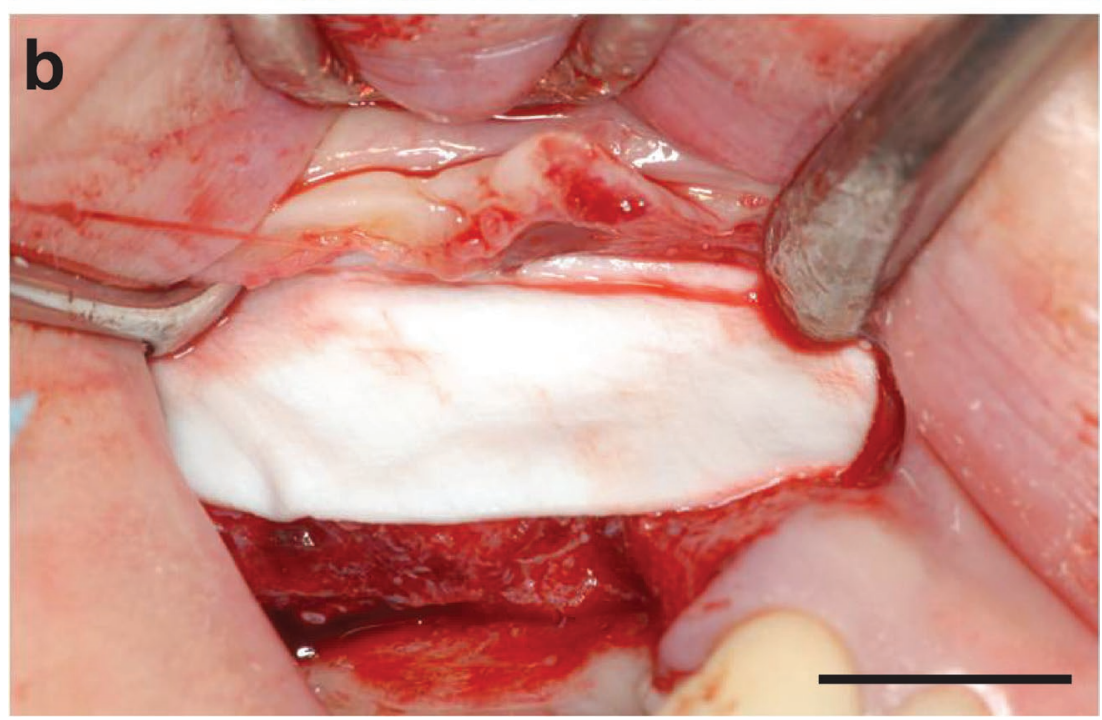

pregnancy were excluded from participation in this study. Patients who required horizontal bone augmentation were also excluded.

\section{Maxillary sinus floor elevation surgery}

In all patients a pre-operative panoramic radiograph was prepared, which was carefully examined for contour lines of the maxillary sinus to determine the bone height at each planned implant position. After the MSFE procedure, using the lateral top-hinge swing door technique according to Tatum (1986), wound healing and ingrowth of bone in the grafted area was allowed for approximately 6 months. Dental implants were then placed as described previously (Frenken et al., 2010). The open space created within the maxillary sinus between the top-hinge trap door and the maxillary sinus floor was filled with $\operatorname{Ceros}^{\circledR} \beta$-TCP granules $(\beta$-TCP) with $60 \%$ porosity and a grain size of $0.7-1.4 \mathrm{~mm}$ (Thommen Medical AG, Waldenburg, Switzerland) (Fig. 1a). In six patients, a resorbable collagenous Biogide ${ }^{\circledR} 25$ x $25 \mathrm{~mm}$ membrane (Geistlich, Wolhusen, Switzerland) was used to cover the lateral window of the maxillary sinus (Fig. 1b; Table 1). Thereafter, the wound was closed using Gore-Tex sutures (W.L. Gore and Associates, Newark, DE, USA), which were removed 10-14 d postoperatively.
All patients received antibiotic prophylaxis, consisting of $500 \mathrm{mg}$ amoxicillin 3-times daily, starting one day preoperatively and continuing one week post-operatively. After a healing period of 6 months, prior to the dental placement a panoramic radiograph was prepared. Both panoramic radiographs, made prior to MSFE and dental implant placement, were used for morphometric measurements to calculate the vertical increase of bone height in the grafted area. Calculations were performed with the use of a conversion factor that adjusted for magnification (1.2 x magnification) of the panoramic radiograph.

Dental implant surgery was performed under local anaesthesia. A crestal incision was made with mesial and distal buccal vertical release incisions. A full-thickness mucoperiosteal flap was raised to expose the underlying alveolar ridge, which was inspected for sufficient bone volume to allow dental implant placement. Then implant preparations were made and biopsies were taken at the planned dental implant positions using a hollow trephine drill with an outer diameter of $3.5 \mathrm{~mm}$, and an inner diameter of $2.5 \mathrm{~mm}$ (Straumann trephine drill, Institute Straumann AG, Basel, Switzerland), using sterile saline for copious irrigation. Regular neck Straumann dental 

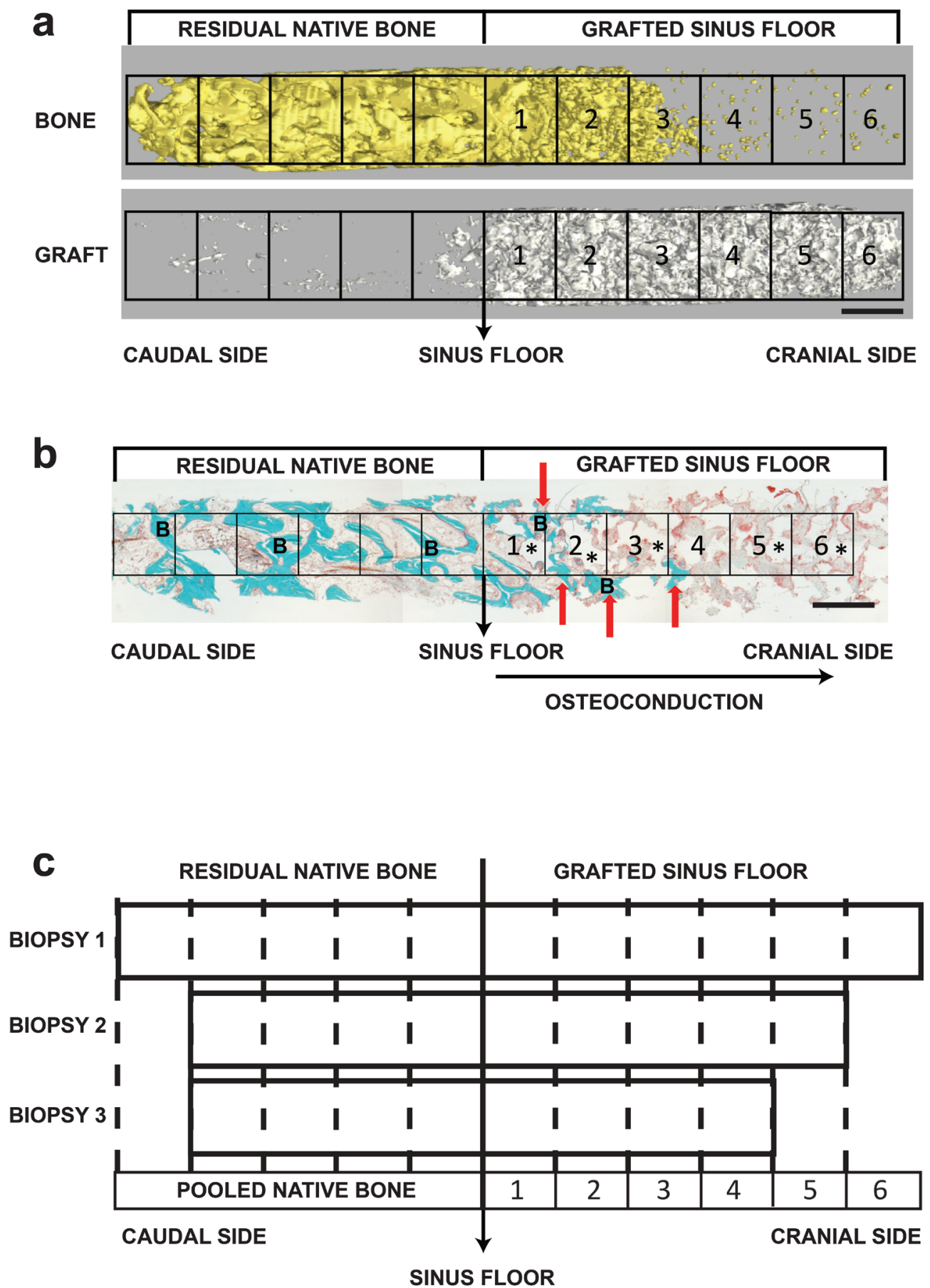

Fig. 2. Micro-CT and histomorphometrical analysis of bone biopsies: methods. (a) Micro-CT analysis showing bone volume and graft volume in a whole biopsy. For micro-CT analysis biopsies were divided in consecutive ROI of $1 \mathrm{~mm}$ thickness, and bone volume as well as graft volume were determined in each ROI. New bone formation in the grafted maxillary sinus floor was determined in the ROI from the sinus floor towards the cranial side of the biopsies, whereby section 1 indicates the first ROI where substantial graft material ( $>1 \%$ graft volume per total volume) was observed when analysing from the caudal to the cranial side of the biopsy. (b) Overview of a mid-sagittal section of a whole biopsy stained with Goldner's Trichome. For histomorphometrical analysis, biopsies were divided in consecutive ROI of $1 \mathrm{~mm}^{2}$. The maxillary sinus floor indicates the border between the residual native bone and the grafted maxillary sinus floor. New bone formation (red arrows) in the grafted sinus floor can be seen around the TCP remnants $(*)$. Bone (B) ingrowth, osteoconduction, is determined from the maxillary sinus floor towards the cranial side of the biopsies. (c) Schematic diagram showing the alignment of the biopsies. Three different biopsies differing in size, and residual maxillary sinus floor vertical bone height, are shown. The biopsies are positioned at a $90^{\circ}$ angle, with the caudal side at the left and the cranial side at the right. All biopsies were divided and analysed in $1 \mathrm{~mm}$ volumes of interest (dotted lines). Data from the residual native bone were pooled. The maxillary sinus floor shows the border (solid line) between the residual native bone and the grafted part of the biopsy with newly formed bone. Each numbered ROI represents the measurements in the grafted sinus floor region of the biopsy. Scale bars represent $1 \mathrm{~mm}$. 
implants with a diameter of $4.1 \mathrm{~mm}$, a length of 10 or $12 \mathrm{~mm}$, and a SLA (sand-blasted, large grit, acid-etched) surface were placed in the augmented maxillary sinus. The dental implants were placed in a single-stage surgical procedure, mounted with healing caps and sutured as described previously (Buser et al., 1991). Sutures were removed 10-14 d post-operatively. Patients were instructed to avoid loading of the dental implants during integration time post-implant surgery. After a 3 months dental implant integration period the superstructures were manufactured and placed in an outpatient clinic.

\section{Biopsy analysis}

The bone biopsies, taken during dental implant surgery using a trephine burr, were fixed in $4 \%$ phosphate-buffered formaldehyde (Klinipath BV, Duiven, The Netherlands). Biopsies were removed from the burrs, transferred to $70 \%$ ethanol, and stored until used for micro-CT analysis and histomorphometry as described below. A pre-selection on the retrieved biopsies was done to obtain comparable samples. To this end, broken biopsies and biopsies taken from non-grafted areas were excluded. Intact biopsies from implant positions in the graft-filled area of the maxillary sinus were selected, based on blinded radiographic selection, for histomorphometrical and micro-CT analyses.

\section{Micro-computed tomography analysis}

Bone biopsies were kept in $70 \%$ ethanol, and threedimensional (3D) reconstructions of the biopsies were obtained using a high-resolution micro-CT system ( $\mu \mathrm{CT}$ 40, Scanco Medical AG, Bassersdorf, Switzerland). To this end, biopsies were fixed in synthetic foam and placed vertically in a polyetherimide holder and scanned at a $10 \mu \mathrm{m}$ isotropic voxel size, $70 \mathrm{kV}$ source voltage, and $113 \mu$ A current. Grey values, depending on radiopacity of the scanned material, were converted into corresponding values of degree of mineralisation by the analysis software (Scanco Medical AG). The distinction between newly formed bone and graft material was made using the highest value of the degree of mineralisation in the pre-existing sinus floor bone as threshold value. Thereby, a distinction could be made between the original non-grafted native bone of the residual sinus floor and the graft material, since the mineralisation degree of the graft material was significantly higher than the mineralisation degree of bone. A low threshold of $650 \mathrm{mg}$ hydroxyapatite (HA) $/ \mathrm{cm}^{3}$ to distinguish bone tissue from connective tissue and bone marrow, and the grey values were scaled from 1 to 1000 and the threshold was set at 270 to distinguish graft material from bone tissue. These two thresholds were calculated by averaging the thresholds determined in 3 slices of three bone biopsies by two independent observers. Using this simple thresholding resulted initially in a thin layer of bone covering the graft material throughout the grafted area of the sinus. Therefore, a new and so called "onion-peeling" algorithm (Scanco Medical AG) was used to discriminate between the newly formed bone deposited on the graft material and the graft material itself. This method peels off voxels from the thin layer of bone (as measured with the simple thresholding), and removes this layer when
$\beta$-TCP was detected within a predefined extent of space. The digital images of the scanned biopsies were analysed, starting from the caudal side of the biopsy, and continuing towards the cranial side (Fig. 2a-c). ROI of $1 \mathrm{~mm}$ thickness were defined. The bone volumes obtained from the ROI in the residual native bone part were pooled. ROI, numbered in a consecutive sequence starting from the residual sinus floor (ROI 1) up to the most cranial part of the biopsy, were analysed for bone volume and graft volume. The following microstructural parameters of the bone were determined: trabecular connectivity density (Conn.D) per $\mathrm{mm}^{3}$, trabecular number (Tb.N) per mm, trabecular thickness (Tb.Th) expressed in $\mathrm{mm}$, trabecular spacing/ separation (Tb.Sp) expressed in $\mathrm{mm}$, and bone mineral density (BMD) expressed in $\mathrm{mg}$ HA per $\mathrm{cm}^{3}$.

\section{Histology and histomorphometrical analysis}

After micro-CT scanning and dehydration in ascending alcohol series, the bone specimens were embedded without prior decalcification in low temperature polymerising methylmethacrylate (MMA, Merck Schuchardt OHG, Hohenbrunn, Germany), as previously described (Zerbo et al., 2004). Longitudinal sections of $5 \mu \mathrm{m}$ thickness were prepared using a Jung $\mathrm{K}$ microtome (R. Jung, Heidelberg, Germany). Midsagittal histological sections of each biopsy were stained with Goldner's Trichome, in order to distinguish mineralised bone tissue (green) and unmineralised osteoid (red) (Plenk, 1989). The histological sections were divided in ROI of $1 \mathrm{~mm}^{2}$ for blinded histomorphometrical analysis. Depending on the length of the biopsy, the number of ROI ranged from 9-15 (Fig. 2b,c). A consecutive section was immuno-stained for tartrateresistant acid phosphatase (TRAP) and counterstained with light green to detect any osteoclast-like cells. TRAP staining was carried out according to the method described by Van de Wijngaert and Burger (1986). For each separate ROI, the histomorphometrical measurements were performed with a computer using an electronic stage table and a Leica DC 200 digital camera. The computer software used was Leica QWin $^{\odot}$ (Leica Microsystems Image Solutions, Rijswijk, The Netherlands). Digital images of the sections were acquired at $100 \mathrm{x}$ magnification. A demarcation line was indicated between the "residual native bone" floor and the regenerated "grafted sinus floor" bone. Consecutive ROI of $1 \mathrm{~mm}^{2}$ each were defined and numbered throughout the whole biopsy. Data from the residual native bone part of the biopsy were pooled. Each ROI from the sinus floor towards the cranial side of the biopsy was analysed separately (Fig. 2b,c). Using this new method we were able to compare similar ROI for all biopsies (with and without membrane) with respect to the bone regeneration in the augmented maxillary sinus as indicated by the amount of osteoid and bone formed, the presence of TRAP-positive multinucleated osteoclasts, and the volume of remaining graft material. In each ROI, the mineralised tissue volume (Md.V), graft volume (GV), and osteoid volume (OV) were calculated as a percentage of the total tissue volume (TV), as previously described (Parfitt et al., 1987). The number of TRAP-positive cells (osteoclasts, N.Oc) was expressed per total tissue area $\left(\mathrm{mm}^{2}\right)$. 
Table 2. Histomorphometrical analysis of complete bone biopsies with or without collagenous barrier membrane.

\begin{tabular}{|l|c|c|c|c|c|}
\hline Treatment & $\begin{array}{c}\text { Mean mineralised } \\
\text { volume (\%) }\end{array}$ & $\begin{array}{c}\text { Mean osteoid } \\
\text { volume (\%) }\end{array}$ & $\begin{array}{c}\text { Mean graft } \\
\text { volume (\%) }\end{array}$ & $\begin{array}{c}\text { Connective tissue and } \\
\text { marrow volume (\%) }\end{array}$ & $\begin{array}{c}\text { Implant } \\
\text { survival (\%) }\end{array}$ \\
\hline Without membrane & $24 \pm 8$ & $0.6 \pm 0.4$ & $19 \pm 10$ & $56 \pm 4$ & 100 \\
\hline With membrane & $19 \pm 4$ & $0.3 \pm 0.1^{\text {a }}$ & $19 \pm 7$ & $62 \pm 5$ & 100 \\
\hline
\end{tabular}

The complete bone biopsies were evaluated using histomorphometry for the mean percentage of bone, osteoid, graft material and connective tissue/marrow. Data on $\geq 1$-year implant survival indicated that no implants failed in the groups

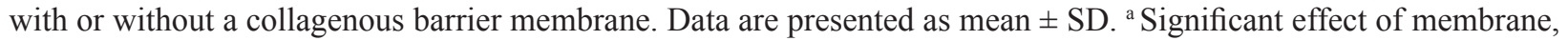
$p<0.05$.

\section{Statistical analysis}

Data are presented as mean \pm standard deviation (SD). Statistical analysis was performed using SPSS version 15.0 software. The Mann-Whitney test was performed to compare results obtained from the different volumes of interest between the biopsies with and without a membrane. Statistical significance was considered when $p<0.05$.

\section{Results}

\section{Clinical evaluation and implant survival}

All MSFE procedures using $\beta$-TCP as a bone grafting material, with or without a collagenous barrier membrane covering the lateral window, were performed without any Schneiderian membrane (antral mucosa) perforation and showed uneventful healing. No wound dehiscences were observed, and no premature membrane exposure occurred. Primary stability was achieved with all dental implants, which demonstrated excellent osseointegration after a healing period of 3 months. No clinical signs of inflammation were observed during follow-up. No implant failures were observed during a follow-up of at least one year in the patient group with a collagenous barrier membrane, nor in the group without a membrane, resulting in a $100 \%$ dental implant survival (Table 2).

\section{Radiological evaluation}

Two panoramic radiographs were made of each patient, i.e. one radiograph was made prior to MSFE (Fig. 3a), and another one prior to dental implant placement (Fig. $3 b$ ). The mean gain in height of the maxillary sinus floor at the implant positions was similar for patients without a membrane (Fig. 3c) and patients with a collagenous barrier membrane (Fig. 3d) (without membrane: $7.8 \pm 1.9 \mathrm{~mm}$; with membrane: $7.2 \pm 1.5 \mathrm{~mm}$; mean $\pm \mathrm{SD})$.

\section{Quantitative histomorphometric evaluation}

To assess osteoconduction and new bone formation in the grafted area, bone biopsies of the corresponding implant positions were embedded, cut into sections, and stained using Goldner's Trichome. Newly formed mineralised bone tissue, containing lacunae with live osteocytes, unmineralised osteoid areas, and connective tissue, were observed around the $\beta$-TCP particles cranial to the native residual bone. Close contact between newly formed bone and bone substitute was observed.
Histomorphometric evaluation of complete biopsies without membrane $(n=6)$ and biopsies with a collagenous barrier membrane $(n=6)$ revealed that the OV/TV was significantly $(p=0.026)$ higher in biopsies without a membrane than with a membrane (Table 2; without membrane: $0.6 \pm 0.4 \%$; with membrane: $0.3 \pm 0.1 \%$ ). No differences between biopsies without and with a membrane were observed with regard to the following histomorphometric parameters: mean percentage of mineralised volume (Table 2; without membrane: 24 $\pm 8 \%$; with membrane: $19 \pm 4 \%$ ), mean percentage of graft volume (Table 2; without membrane: $19 \pm 10 \%$; with membrane: $19 \pm 7 \%$ ), mean percentage of connective tissue and marrow volume (Table 2; without membrane: $56 \pm 4 \%$; with membrane: $62 \pm 5 \%$ ), and mean number of osteoclasts (Table 2; without membrane: $1.8 \pm 1.8$, with membrane: $0.6 \pm 0.5)$.

To gain insight into whether the distribution of the values of the histomorphometric parameters was homogeneous or not, throughout the residual bone and the newly formed bone, biopsies were divided in consecutive ROI - which were then analysed separately (Fig. 2b). The bone ingrowth from the native residual alveolar bone towards the cranial side of the biopsy was similar in both patient groups without and with a membrane (without membrane: $3 \pm 0.9 \mathrm{~mm}$; with membrane: $2.8 \pm 1.2 \mathrm{~mm}$ ) (Fig. 4a). This indicates that the rate of osteoconduction was $0.5 \mathrm{~mm}$ per month for both groups. The residual native bone was predominantly composed of lamellar bone, containing little osteoid, and some multinucleated TRAP-positive osteoclasts. In all biopsies (without and with membrane) the newly formed bone volume decreased substantially from the residual native bone towards the cranial side of the biopsies (ROI 1-7; Fig. 4b). No graft was observed in the residual native bone. The graft volume increased from the residual native bone towards the more apical side of the biopsies (ROI 1-3; Fig. 4c), and was $40 \%$ at the most apical ROI of the bone biopsies (ROI 4-7; Fig. 4c). In all biopsies (without and with membrane) the unmineralised osteoid volume was clearly more prominent in the newly formed bone area (Fig. 4d). The osteoid volume in all ROI of the grafted area in the biopsies without a membrane was higher than in the biopsies with a membrane, with a significant difference between the groups in ROI 3 and 4 (Fig. 4d).

Multinucleated TRAP-positive osteoclasts were observed predominantly close to the residual native bone 

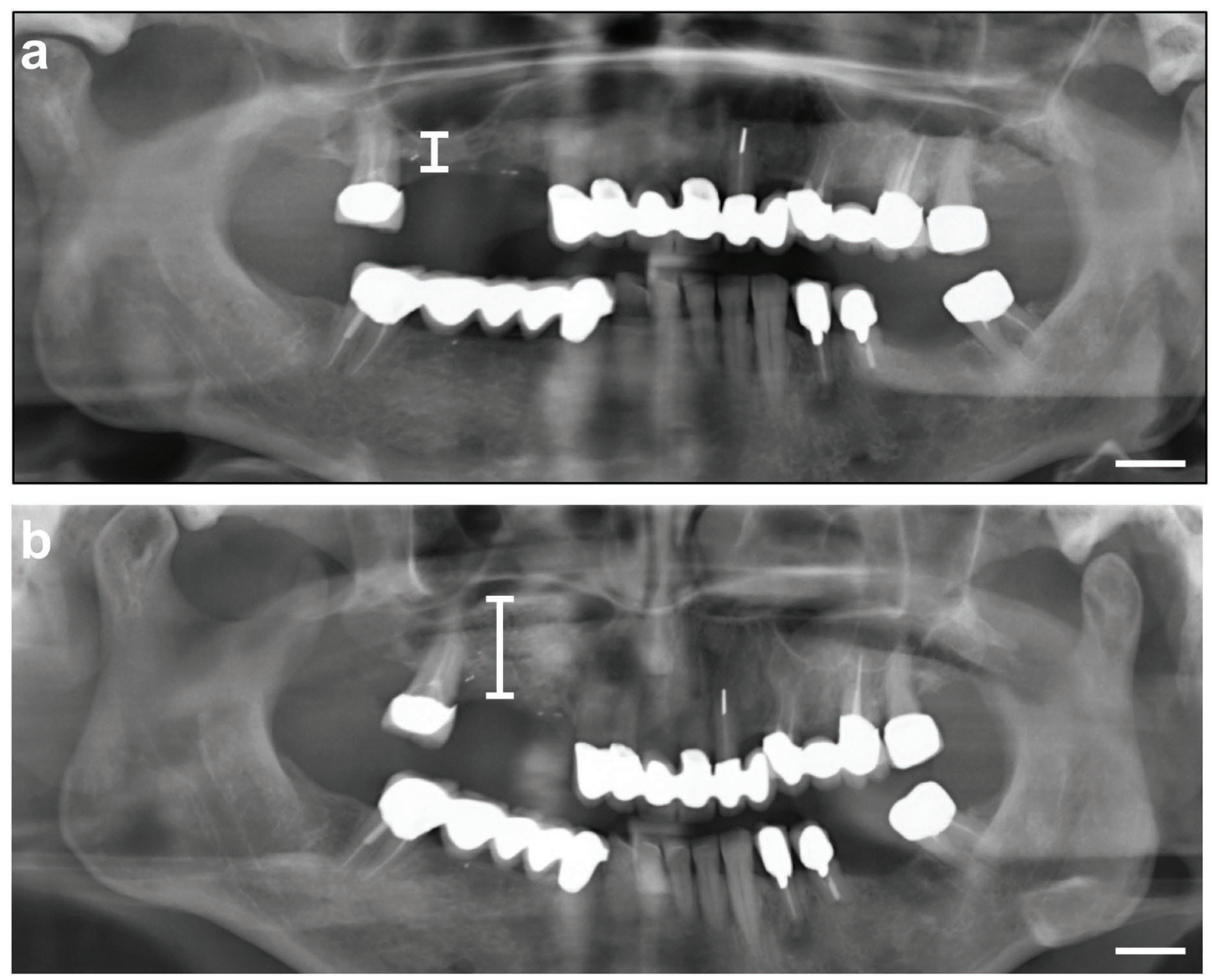

C

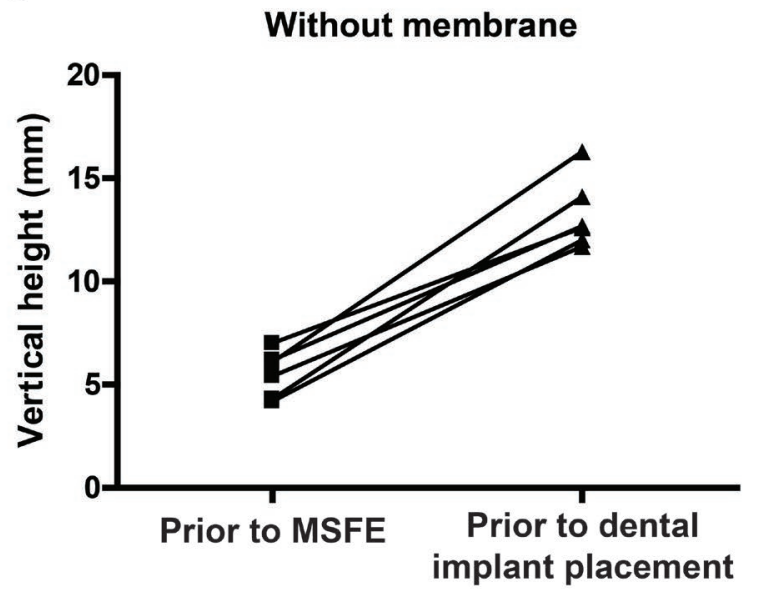

d

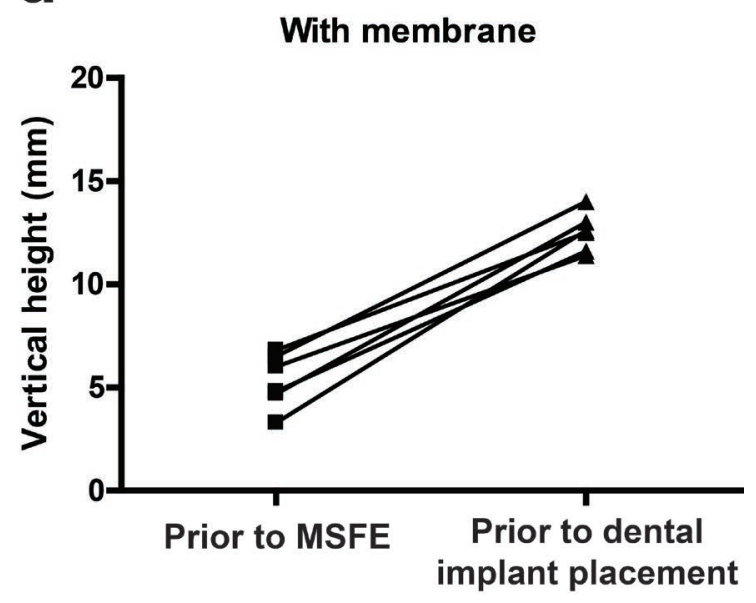

Fig. 3. Radiographic evaluation of the bone height prior to MSFE and prior to dental implant placement. (a) Bone height in the posterior maxilla on panoramic radiographs at the planned dental implant position prior to MSFE, and (b) 6 months after MSFE (prior to dental implant placement). (c) Evaluation of the bone height (in $\mathrm{mm}$ ) prior to MSFE and prior to dental implant placement for patients augmented with $\beta$-TCP Ceros ${ }^{\circledR}>0.7 \mathrm{~mm}(n=6$ patients $)$, and (d) for patients augmented with $\beta$-TCP $\operatorname{Ceros}^{\circledR}>0.7 \mathrm{~mm}$ in combination with a collagenous barrier membrane ( $n=6$ patients). Mean increase in bone height \pm SD was $7.8 \pm 1.9 \mathrm{~mm}$ without membrane and $7.2 \pm 1.5 \mathrm{~mm}$ with a collagenous barrier membrane. Scale bars represent $1 \mathrm{~cm}$.

in biopsies without and with membrane (ROI 1-3; Fig. 5a), indicating that active bone remodelling was taking place. TRAP-positive osteoclasts were absent in ROI with little or no newly formed bone (ROI 4-7; Fig. 5b).
No significant differences were observed in the mean number of osteoclasts between biopsies without or with a collagenous barrier membrane. 

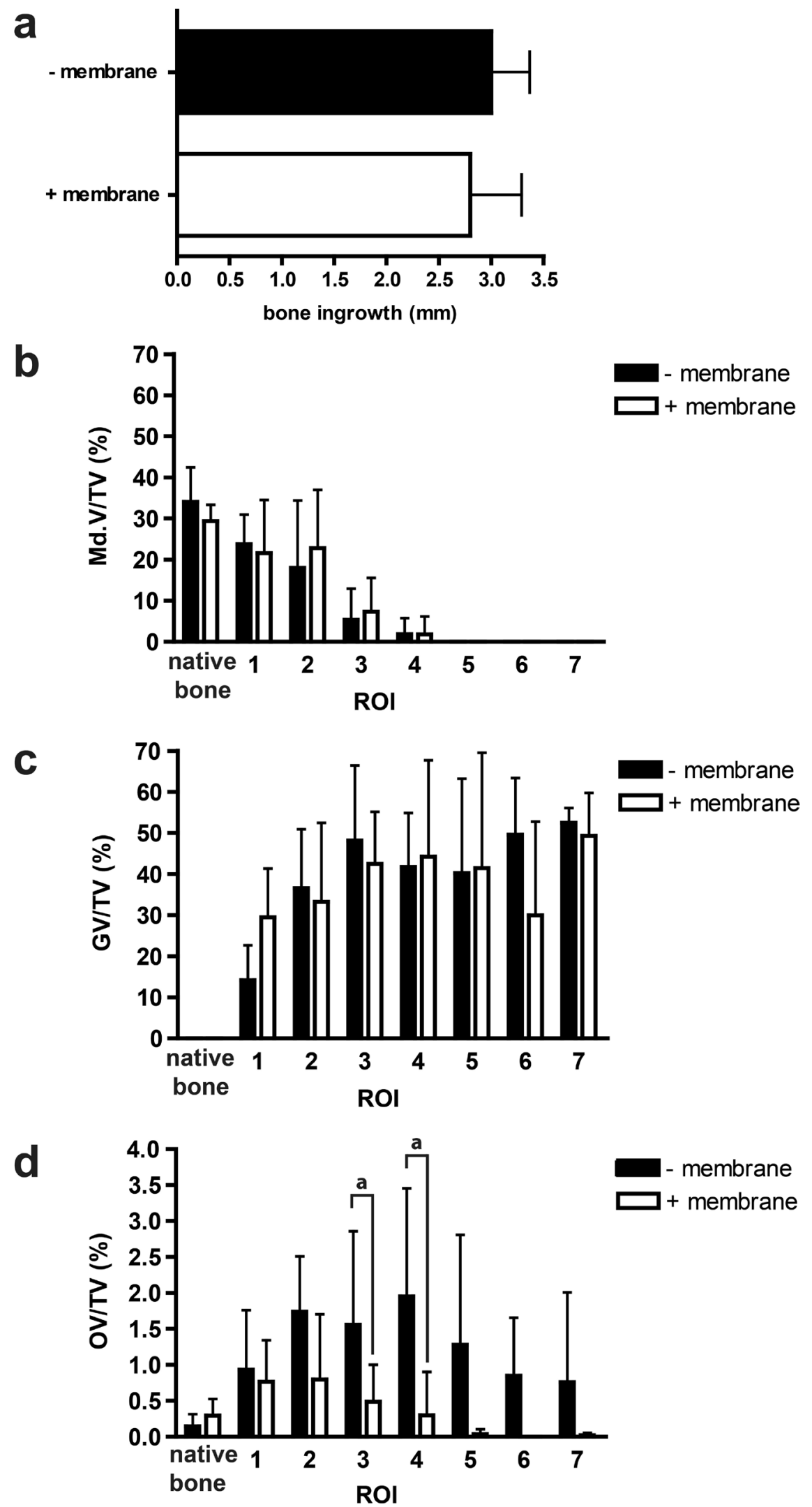

Fig. 4. Histomorphometrical analysis of bone biopsies with and without collagenous barrier membrane. Bone ingrowth (osteoconduction) in $\mathrm{mm}$ was determined from the maxillary sinus floor towards the cranial side of the biopsies. Data are presented as mean $\pm \mathrm{SD}$, and were similar for both patient groups; without membrane: $3 \pm 0.9 \mathrm{~mm}$; with membrane: $2.8 \pm 1.2 \mathrm{~mm}$. (a) Osteoconduction rate for both groups was $0.5 \mathrm{~mm}$ per month. Histomorphometrical analysis of (b) the mineralised bone volume (Md.V), (c) graft volume (GV), and (d) osteoid volume (OV) as a percentage of the total tissue volume (TV) per area for the group without (-) membrane (black bars) and the group with $(+)$ a collagenous barrier membrane (white bars). Data are presented as mean \pm SD. For both groups (with and without membrane), 6 biopsies were analysed, and only ROI with data from at least 3 biopsies are shown $(n \geq 3)$. Significantly different, $p<0.05$. 


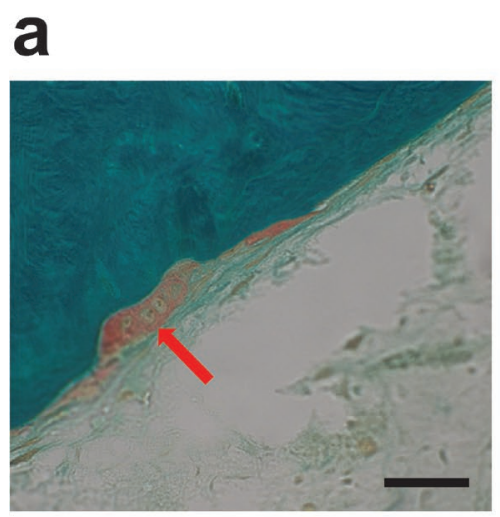

b

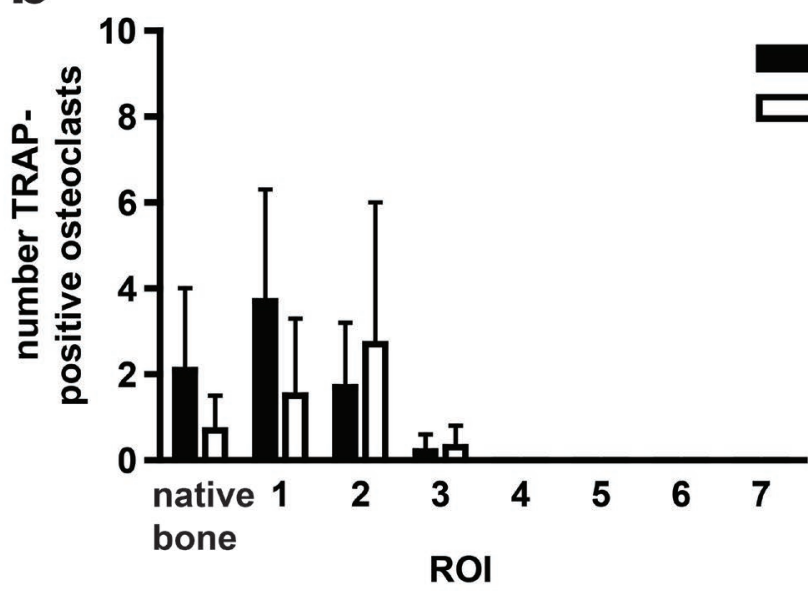

- membrane + membrane

Fig. 5. Osteoclast activity in bone biopsies with and without a collagenous barrier membrane. (a) To visualise osteoclasts within the bone biopsies, consecutive sections were stained for tartrate-resistant acid phosphatase (TRAP; red stain). An example of a large TRAP-positive, multinuclear osteoclast laying on a piece of bone is depicted by a red arrow. (b) The number of TRAP-positive osteoclasts was counted in each separate ROI in each biopsy. Measurements from the native bone part, without graft, were pooled. Each numbered ROI represents the number of osteoclasts in the grafted part of the biopsy. Data are presented as mean \pm standard deviation. For both groups, without (-) membrane (black bars) and with (+) a collagenous barrier membrane (white bars), 6 biopsies were analysed, and only ROI with data from at least 3 biopsies are shown $(n \geq 3)$. Scale bar represent $25 \mu \mathrm{m}$.

\section{Micro-computed tomography evaluation}

For 3D analysis and evaluation, bone biopsies were scanned using micro-CT. The biopsies were divided in ROI of $1 \mathrm{~mm}$ volumes of interest and micro-CT analysis was performed on each consecutive ROI (Fig. 2a). Using this method a clear distinction could be made between graft and bone. The bone ingrowth into the graft-filled area could be clearly visualised (Fig. 6a-c), and quantified (Fig. 6d,e). The mineralised bone volume decreased substantially from the residual native bone towards the cranial side of the biopsies (ROI 1-5; Fig. 6d). This pattern corresponded to our observations using histomorphometry (Fig. 4b). As expected, no graft was observed in the residual native bone, and percentages of graft volume were increasing from the ROI close to the sinus floor towards those at the apical side of the biopsies (ROI 1-3; Fig. 6e). The graft volume remained rather constant $(\sim 20 \%)$ throughout the more apical side of the biopsies (ROI 4-7; Fig. 6e).

To shed more light on the microarchitectural parameters of the newly formed bone in the graft-filled area, and to compare these parameters with those in the residual native bone, micro-CT was used to analyse bone mineral density, trabecular number, trabecular thickness, trabecular spacing, and trabecular connectivity density. The latter was highest close to the border between the residual native bone and the grafted sinus floor (ROI 1-2; Fig. 7a). In these ROI a slightly higher number of trabeculae was observed (Fig. 7b) as well as a lower trabecular thickness (Fig. 7c), and less space between the trabeculae (Fig. 7d). The ROI at the apical side of the biopsies (ROI 3-5) demonstrated a decreased number of trabeculae. These trabeculae were also thinner, and consequently there was more space between the trabeculae, when compared to the ROI at the caudal side of the biopsies (residual native bone and ROI 1-2; Fig. 7b- d). The 3D reconstructions (Fig. 6a-c) clearly represented these findings on trabecular structural parameters. The bone mineral density of the newly formed bone in the graft-filled area was lower than the bone mineral density of the native bone (Fig. 7e). No significant differences in the micro-architectural parameters were observed between the biopsies without and with collagenous barrier membrane.

\section{Discussion}

The aim of this study was to assess whether covering the lateral window with a resorbable collagenous barrier membrane during augmentation of the maxillary sinus floor with $\beta$-TCP is beneficial for bone regeneration. Evaluation was performed by multiparameter analysis, i.e. by combining clinical, radiological, histological, histomorphometrical and micro-CT data. The latter two data sets were analysed using a novel approach, in which consecutive $1 \mathrm{~mm}$ ROI were defined, thus allowing identification of new bone formation in a highly detailed manner. Using this novel approach it was shown that after a healing period of 6 months, $\beta$-TCP is an effective bone substitute for pre-implant vertical bone augmentation in the human maxillary sinus with high survival rates of dental implants. Moreover, it was demonstrated that the use of a resorbable collagenous barrier membrane covering the lateral window during MSFE procedures did not affect mineralised bone volume (24\% without versus $19 \%$ with membrane), but decreased the amount of osteoid, which might indicate either less active osteoblasts and/ or an inhibition of the ingrowth of active osteoblasts in these bone biopsies. 
a

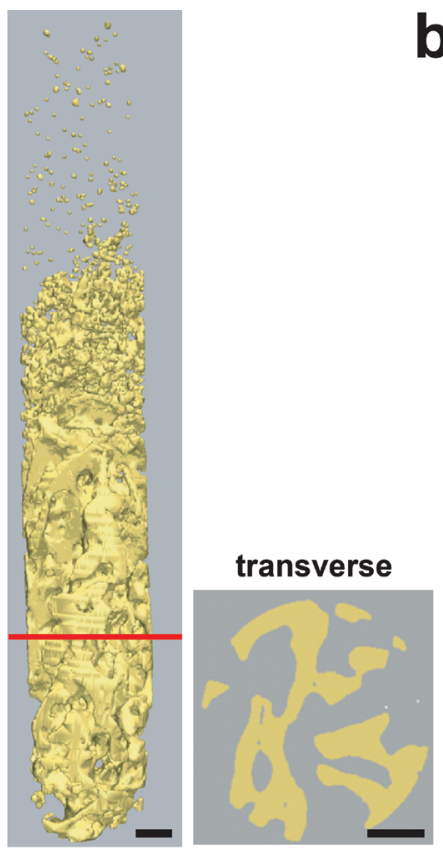

Bone

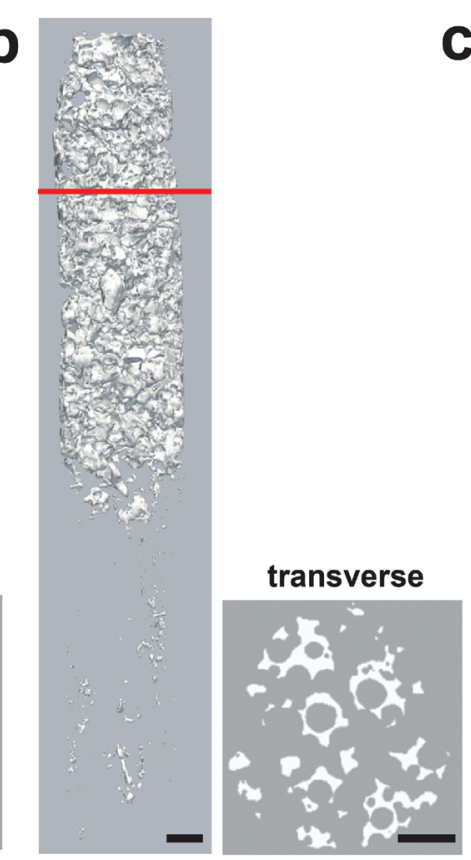

Graft

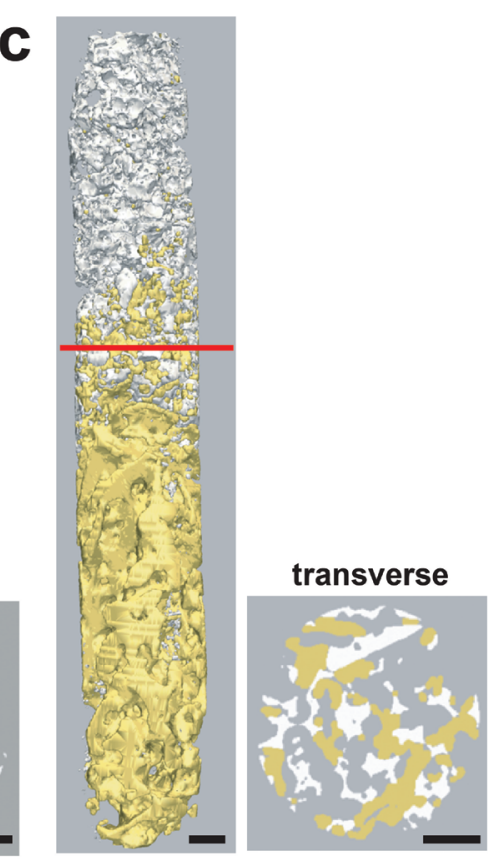

Bone\&Graft

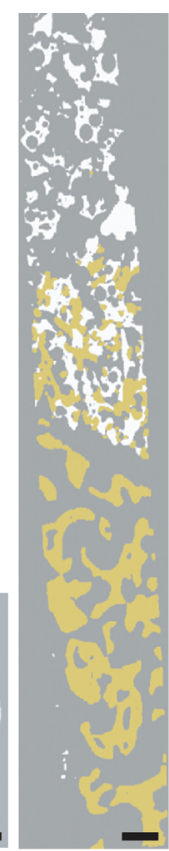

midsagittal

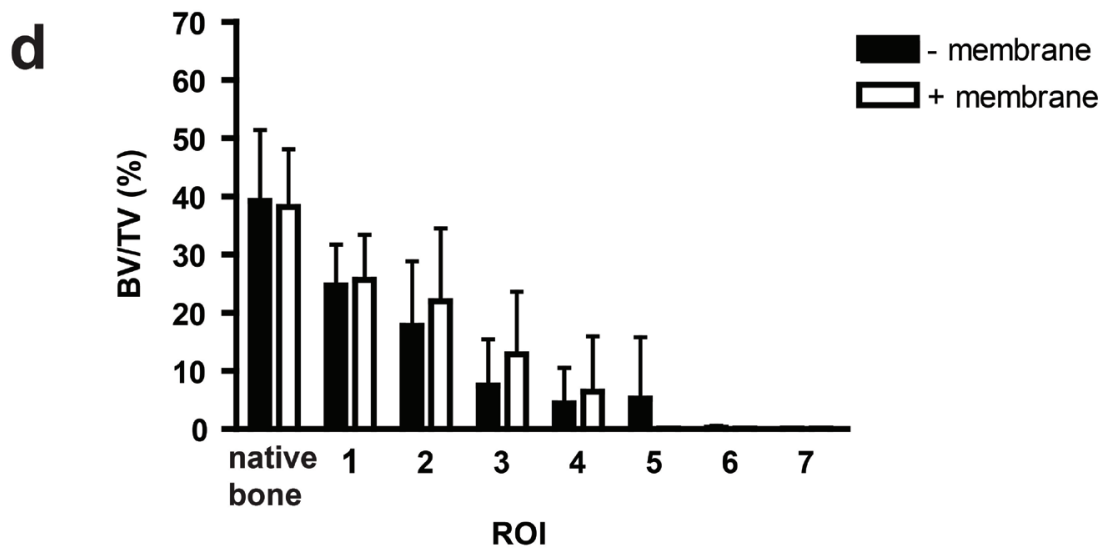

e

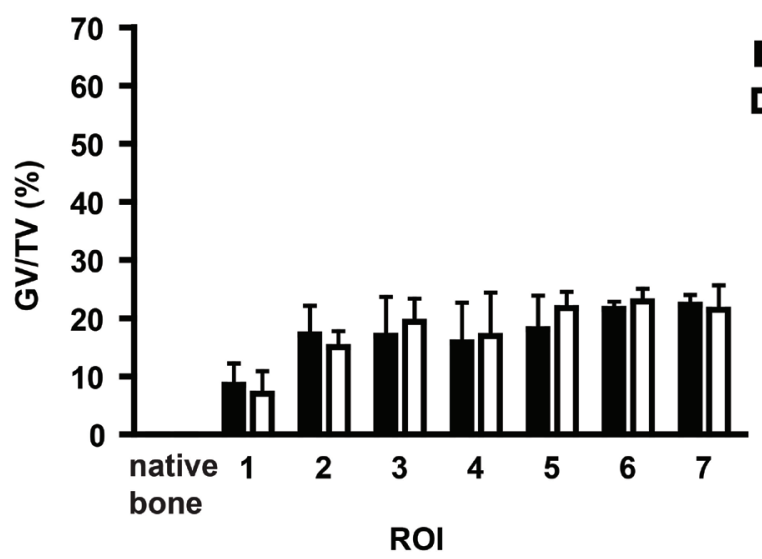

Fig. 6. Micro-CT evaluation of bone biopsies with and without collagenous barrier membrane: bone and graft volume. Micro-CT was used to create 3D reconstructions of the biopsies. (a) Total bone volume (yellow), (b) total graft volume (white), and (c) the combination of bone (yellow) and graft (white) are shown. The red line indicates the position where the transverse sections were made. For the combination of bone and graft a mid-sagittal section is shown in (c). To evaluate bone and graft volumes, biopsies were divided in consecutive ROI of $1 \mathrm{~mm}$ (see Fig. 2a). The residual native bone part of the biopsies contained less than $0.2 \%$ graft. (d) Bone volume (BV) and (e) graft volume $(\mathrm{GV})$ are shown as a percentage of the total tissue volume (TV). Data are presented as mean $\pm \mathrm{SD}$. For both groups, without (-) membrane (black bars) and with $(+)$ collagenous barrier membrane (white bars), 6 biopsies were analysed, and only ROI with data from at least 3 biopsies are shown $(n \geq 3)$. Scale bars represent $500 \mu \mathrm{m}$. 
Fig. 7. Micro-CT evaluation of bone biopsies with and without a collagenous barrier membrane: micro-architectural parameters. Micro-CT was used to evaluate the structural parameters of the newly formed bone. Biopsies were divided in consecutive ROI of $1 \mathrm{~mm}$ length (Fig. 2a), and in each slice the following parameters were determined: (a) the trabecular connectivity density (Conn.D) per $\mathrm{mm}^{3}$, (b) the trabecular number (Tb.N) per mm, (c) trabecular thickness (Tb.Th) expressed in $\mathrm{mm}$, (d) trabecular spacing/ separation (Tb.Sp) expressed in $\mathrm{mm}$ and (e) bone mineral density (BMD) expressed in $\mathrm{mg} \mathrm{HA} \mathrm{per} \mathrm{cm}^{3}$. Measurements from the native bone part, without graft, were pooled. Each numbered ROI represents the measurements in the grafted part of the biopsy. Data are presented as mean $\pm \mathrm{SD}$. For both groups, without (-) membrane (black bars) and with $(+)$ a collagenous barrier membrane (white bars), 6 biopsies were analysed, and only ROI with data from at least 3 biopsies are shown $(n \geq 3)$. a

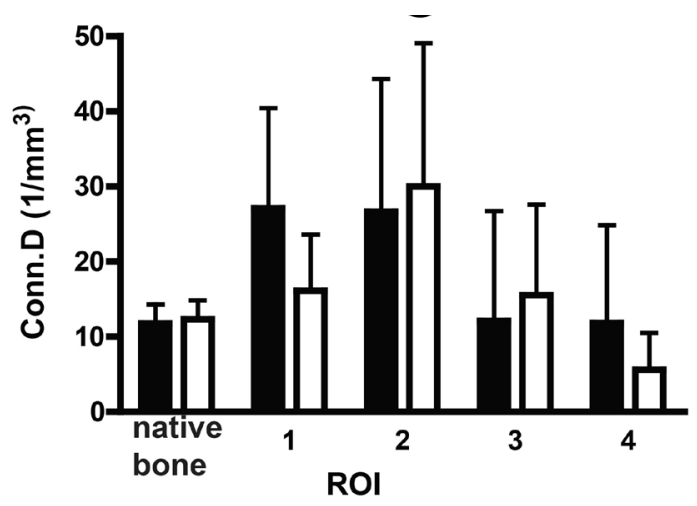

b

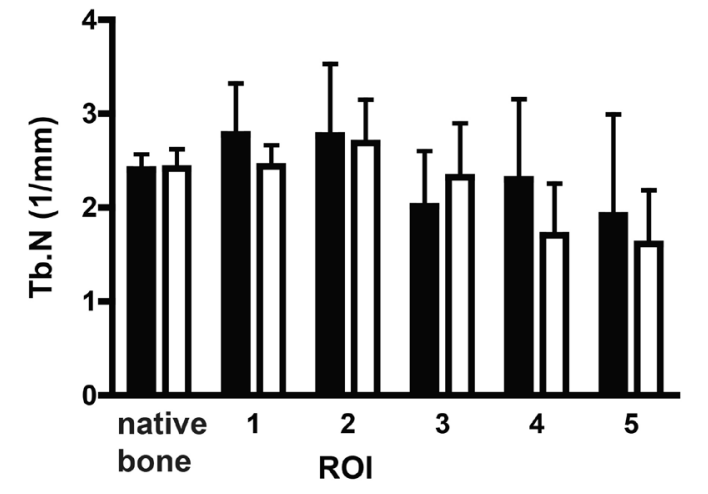

C

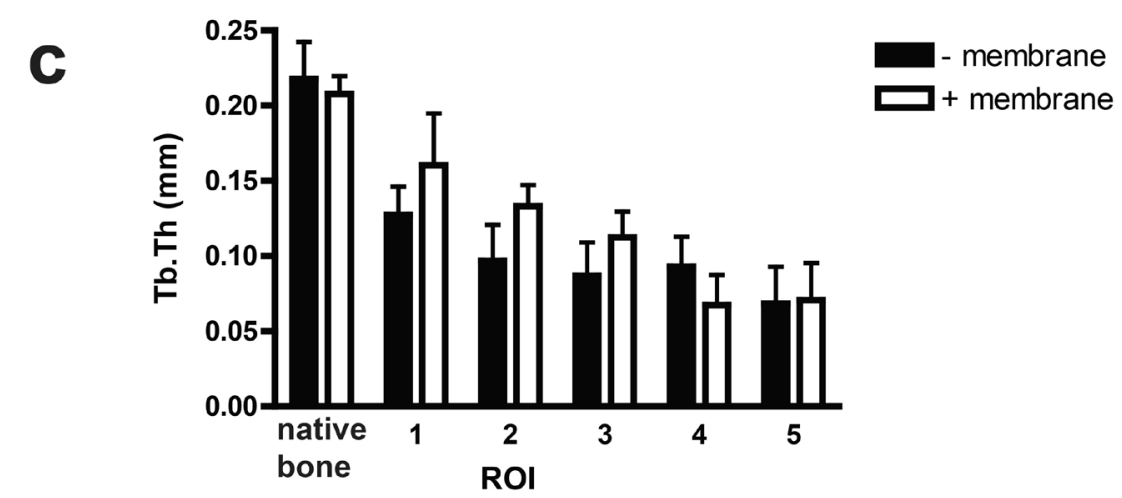

d
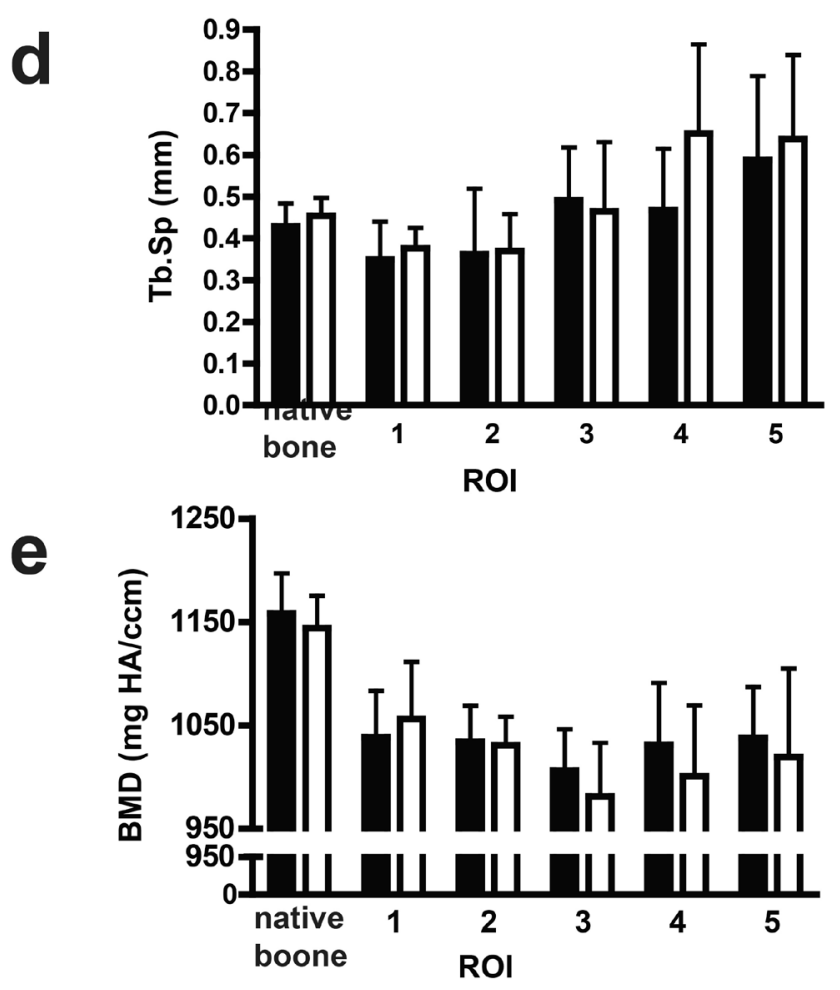

- membrane

$\square+$ membrane

- membrane

$\square+$ membrane

(1)

(1) 
Our novel approach to obtain highly detailed information on new bone formation in the grafted area provides solutions for both the residual native bone height in the posterior maxilla (which hampers correct statements about the extent of new bone formation), and allows assessment of the spatial distribution of the newly formed bone throughout the grafted maxillary sinus. First, the biopsies are divided in consecutive $1 \mathrm{~mm}$ ROI. Subsequently, bone biopsies are aligned at the remaining maxillary sinus floor bone height, allowing separation of bone volume data in the residual bone part, and those of the newly formed bone in the graft-filled area of the augmented maxillary sinus. Finally, histomorphometrical data are determined in each ROI, thus allowing identification of new bone formation in a highly detailed manner.

The histomorphometrical data were compared with the results of the micro-CT analysis of the biopsies, using similar ROI. By using a unique "onion-peeling" algorithm and specific threshold settings, we were able to distinguish between native bone and grafted ROI, and to gain insight into the 3D structure of the bone grown into the grafted maxillary sinus floor. Minor differences between histomorphometrical results and micro-CT results could be attributed to small differences in 2D and 3D measurements. Lower percentages of graft volume were observed by micro-CT analysis compared to histomorphometry throughout all grafted ROI in biopsies with or without membrane. This might be explained by the fact that graft volumes are massive when analysed by histomorphometry but not by micro-CT, although the structure of the $\beta$-TCP granules used was porous. The percentage of graft volume was approximately two-fold lower when analysed by micro-CT compared to histomorphometry, which is in line with the porosity of $60 \%$ of the $\beta$-TCP granules. These results indicate that micro-CT is highly useful for $3 \mathrm{D}$ evaluation of bone regeneration in MSFE.

Using our novel approach, we demonstrate that osteoconduction exclusively occurred upwards from the maxillary sinus floor in a cranial direction, independently of the placement of a collagenous barrier membrane, and that no bone ingrowth had taken place from the lateral sides of the biopsies. This indicates that close contact of the graft material with a bony environment was required for new bone formation in the grafted area, and that the osteoprogenitor cells that repopulate the grafted maxillary sinus floor were mainly derived from cells residing in the residual maxillary alveolar ridge. No differences were observed between bone formation volumes between both patient groups. This is in concordance with a recent metaanalysis by Klijn et al. (2010), showing no significant effect of the use of a (non-)resorbable membrane over the lateral window on the amount of total bone volume of various biomaterials as sinus floor augmentation materials. Remarkably, even a decrease in the amount of osteoid formed and an increase in the percentage of connective/fibrous tissue was observed in the grafted area of the biopsies in membrane-covered compared to uncovered MFSEs, thereby also potentially affecting bone regeneration at the position where the dental implants were placed.
Our data are in contrast with observations by Wallace et al. (2005), who concluded that vital bone formation in MSFE procedures using deproteinised bovine bone mineral $\left(\mathrm{Bio}^{-O s s^{\circledR}}{ }^{\circledR}\right.$ as grafting material is improved when a barrier membrane, either the same bioresorbable BioGide $^{\circledR}$ membrane as used in our study or a non-resorbable Gore-Tex ${ }^{\circledR}$ membrane, was placed over the lateral window. However, in the Wallace study the beneficial effect appeared to be primarily caused by a rather low vital bone percentage $(12.1 \%$ versus $17.6 \%$ in the membrane groups), whereas other studies found substantial higher bone percentages by using Bio-Oss ${ }^{\circledR}$ without a membrane (Valentini et al., 2000; John and Wenz, 2004; Cordaro et al., 2008).

Differences in degradation of deproteinised bovine bone xenograft, such as Bio-Oss ${ }^{\circledR}$, and calcium phosphate ceramics, such as $\beta$-TCP, might explain different results obtained when using these two materials in MSFE. A pre-clinical dog study shows that $\beta$-TCP particles are completely resorbed 24 months after implantation, whereas no significant resorption of inorganic xenograft is observed beyond 6 months (Artzi et al., 2004). Bio-Oss degrades very slowly (Meijndert et al., 2005); no clinical signs of resorption are seen up to 6 years (Schlegel and Donath, 1998). Graft materials with a very low resorption rate will not remodel and thus not functionally adapt to surrounding bone, which might result in negative mechanical cues. Slow or even a lack of resorption of graft material prevents its replacement by new bone, which may hamper proper and timely bone to dental implant interface formation, thus possibly resulting in lower implant survival. However, the clinical relevance of these differences in degradation rate and/or whether the effect of a collagenous barrier membrane is similar in combination with other types, shapes and sizes of graft materials, such as injectable cements, and any other application needs further (pre-) clinical investigation, especially on the long term changes.

Last but not least: the collagenous barrier membrane is composed of collagen extracted from animals, i.e. veterinary certified pigs, and the use of and exposure to animal-derived materials in clinical settings should be prevented as much as possible. The benefits of using a xenogenic collagenous barrier membrane in combination with any graft material should be considered very carefully, and only be used when benefits have been irrefutably proven.

\section{Conclusions}

The MSFE procedure represents a unique human model, since after this procedure, clinical bone biopsies can be taken and studied (Farré-Guasch et al., 2013). In the current study, using an innovative multiparametric analysis in combination with a novel "onion-peeling" algorithm and a unique $1 \mathrm{~mm}$ ROI evaluation strategy, we optimised MSFE biopsy evaluation by establishing a novel strategy that allows identification and spatial distribution of new bone formation in a highly detailed manner, and simultaneously provides a solution for the amount of residual native bone height. 
Using this novel approach, we demonstrated that the use of a resorbable collagenous barrier membrane covering the lateral window during MSFE procedures - using $\beta$-TCP as a grafting material - did not have any beneficial effects on: the bone ingrowth into the grafted area; the prevention of ingrowth of fibrous tissue into the grafted area; or, the survival of dental implants. The collagenous barrier membrane even decreased the amount of osteoid, which might lead to an inhibition of bone formation in the long run.

The value of the MSFE procedure reaches far beyond the maxillary reconstruction per se, since it allows detailed and microscopic clinical evaluation of all types of novel therapies, such as stem cell-seeded bone substitutes for bone regeneration. Our novel approach may thus represent a pivotal prerequisite for adequate evaluation of innovative bone therapeutic modalities, and may be used to measure safety and efficacy in clinical trials.

\section{Acknowledgements}

This research was supported by ZonMw - The Netherlands Organisation for Health Research and Development (project number 116001009). The authors thank Marion van Duin and Peter Brugman (Departments of Oral Cell Biology and Functional Anatomy, ACTA-UvA and VU University Amsterdam) for excellent technical assistance, Elisabeth Farré-Guasch (Department of Oral and Maxillofacial Surgery, International University of Catalonia, Spain) for help with histomorphometrical analysis, and Britt van den Berg, Leo van Ruiven, and Geerling Langenbach (Departments of Oral Cell Biology and Functional Anatomy, ACTA-UvA and VU University Amsterdam) for help with micro-CT analysis. We wish to confirm that there are no known conflicts of interest associated with this publication and there has been no significant financial support for this work that could have influenced its outcome.

\section{References}

Arrington ED, Smith WJ, Chambers HG, Bucknell AL, Davino NA (1996) Complications of iliac crest bone graft harvesting. Clin Orthop Relat Res 329: 300-309.

Artzi Z, Weinreb M, Givol N, Rohrer MD, Nemcovsky CE, Prasad HS, Tal H (2004) Biomaterial resorption rate and healing site morphology of inorganic bovine bone and beta-tricalcium phosphate in the canine: a 24-month longitudinal histologic study and morphometric analysis. Int J Oral Maxillofac Implants 19: 357-368.

Becktor JP, Hallstrom H, Isaksson S, Sennerby L (2008) The use of particulate bone grafts from the mandible for maxillary sinus floor augmentation before placement of surface-modified implants: results from bone grafting to delivery of the final fixed prosthesis. J Oral Maxillofac Surg 66: 780-786.

Beirne JC, Barry HJ, Brady FA, Morris VB (1996) Donor site morbidity of the anterior iliac crest following cancellous bone harvest. Int J Oral Maxillofac Surg 25: 268-271.

Borstlap WA, Heidbuchel KL, Freihofer HP, KuijpersJagtman AM (1990) Early secondary bone grafting of alveolar cleft defects. A comparison between chin and rib grafts. J Craniomaxillofac Surg 18: 201-205.

Burchardt H (1983) The biology of bone graft repair. Clin Orthop Relat Res 174: 28-42.

Buser D, Schenk RK, Steinemann S, Fiorellini JP, Fox $\mathrm{CH}$, Stich H (1991) Influence of surface characteristics on bone integration of titanium implants. A histomorphometric study in miniature pigs. J Biomed Mater Res 25: 889-902.

Chan K, Resnick D, Pathria M, Jacobson J (2001) Pelvic instability after bone graft harvesting from posterior iliac crest: report of nine patients. Skeletal Radiol 30: 278281.

Cordaro L, Bosshardt DD, Palattella P, Rao W, Serino G, Chiapasco M (2008) Maxillary sinus grafting with Bio-Oss or Straumann Bone Ceramic: histomorphometric results from a randomized controlled multicenter clinical trial. Clin Oral Implants Res 19: 796-803.

Dimitriou R, Mataliotakis GI, Calori GM, Giannoudis PV (2012) The role of barrier membranes for guided bone regeneration and restoration of large bone defects: current experimental and clinical evidence. BMC Med 10: 81 .

Farré-Guasch E, Prins H-J, Overman JR, Ten Bruggenkate CM, Schulten EA, Helder MN, Klein-Nulend J (2013) Human maxillary sinus floor elevation as a model for bone regeneration enabling the application of one-step surgical procedures. Tissue Eng Part B Rev 19: 69-82.

Frenken JW, Bouwman WF, Bravenboer N, Zijderveld SA, Schulten EA, ten Bruggenkate CM (2010) The use of Straumann Bone Ceramic in a maxillary sinus floor elevation procedure: a clinical, radiological, histological and histomorphometric evaluation with a 6-month healing period. Clin Oral Implants Res 21: 201-208.

Iturriaga MT, Ruiz CC (2004) Maxillary sinus reconstruction with calvarium bone grafts and endosseous implants. J Oral Maxillofac Surg 62: 344-347.

Jakse N, Seibert FJ, Lorenzoni M, Eskici A, Pertl C (2001) A modified technique of harvesting tibial cancellous bone and its use for sinus grafting. Clin Oral Implants Res 12: 488-494.

John HD, Wenz B (2004) Histomorphometric analysis of natural bone mineral for maxillary sinus augmentation. Int J Oral Maxillofac Implants 19: 199-207.

Kalk WW, Raghoebar GM, Jansma J, Boering G (1996) Morbidity from iliac crest bone harvesting. J Oral Maxillofac Surg 54: 1424-1429.

Klijn RJ, Meijer GJ, Bronkhorst EM, Jansen JA (2010) A meta-analysis of histomorphometric results and graft healing time of various biomaterials compared to autologous bone used as sinus floor augmentation material in humans. Tissue Eng Part B Rev 16: 493-507.

Meijndert L, Raghoebar GM, Schüpbach P, Meijer HJ, Vissink A (2005) Bone quality at the implant site after reconstruction of a local defect of the maxillary anterior ridge with chin bone or deproteinised cancellous bovine bone. Int J Oral Maxillofac Surg 34: 877-884.

Nwoku AL, Al Atel A, Al Shlash S, Oluyadi BA, Ismail S (2005) Retrospective analysis of secondary alveolar cleft 
grafts using iliac of chin bone. J Craniofac Surg 16: 864868.

Oppenheimer AJ, Tong L, Buchman SR (2008) Craniofacial bone grafting: Wolff's law revisited. Craniomaxillofac Trauma Reconstr 1: 49-61.

Owens KW, Yukna RA (2001) Collagen membrane resorption in dogs: a comparative study. Implant Dent 10: 49-58.

Parfitt AM, Drezner MK, Glorieux FH, Kanis JA, Malluche H, Meunier PJ, Ott SM, Recker RR (1987) Bone histomorphometry: standardization of nomenclature, symbols, and units. Report of the ASBMR Histomorphometry Nomenclature Committee. J Bone Miner Res 2: 595-610.

Plenk H Jr (1989) Bone tissue and teeth. In: Böck P (ed) Romeis Microscopic Technique, 17th ed. Urban \& Schwarzenberg, Munich, Chapter 25, pp 527-566.

Raghoebar GM, Louwerse C, Kalk WW, Vissink A (2001) Morbidity of chin bone harvesting. Clin Oral Implants Res 12: 503-507.

Raghoebar GM, Meijndert L, Kalk WW, Vissink A (2007) Morbidity of mandibular bone harvesting: a comparative study. Int $\mathrm{J}$ Oral Maxillofac Implants 22: 359-365.

Schlegel AK, Donath K (1998) BIO-OSS - a resorbable bone substitute? J Long Term Eff Med Implants 8: 201-209.

Simunek A, Kopecka D, Somanathan RV, Pilathadka S, Brazda T (2008) Deproteinized bovine bone versus beta-tricalcium phosphate in sinus augmentation surgery: a comparative histologic and histomorphometric study. Int J Oral Maxillofac Implants 23: 935-942.

Sindet-Pedersen S, Enemark H (1990) Reconstruction of alveolar clefts with mandibular or iliac crest bone grafts: a comparative study. J Oral Maxillofac Surg 48: 554-558.

Springfield D (1996) Autograft reconstructions. Orthop Clin North Am 27: 483-492.

Suba Z, Takacs D, Matusovits D, Barabas J, Fazekas A, Szabo G (2006) Maxillary sinus floor grafting with beta-tricalcium phosphate in humans: density and microarchitecture of the newly formed bone. Clin Oral Implants Res 17: 102-108.

Szabo G, Huys L, Coulthard P, Maiorana C, Garagiola U, Barabas J, Nemeth Z, Hrabak K, Suba Z (2005) A prospective multicenter randomized clinical trial of autogenous bone versus beta-tricalcium phosphate graft alone for bilateral sinus elevation: histologic and histomorphometric evaluation. Int J Oral Maxillofac Implants 20: 371-381.

Tarnow DP, Wallace SS, Froum SJ, Rohrer MD, Cho SC (2000) Histologic and clinical comparison of bilateral sinus floor elevations with and without barrier membrane placement in 12 patients: Part 3 of an ongoing prospective study. Int J Periodontics Restorative Dent 20: 117-125.

Tatum H Jr. (1986) Maxillary and sinus implant reconstructions. Dent Clin North Am 30: 207-229.

Thorwarth M, Srour S, Felszeghy E, Kessler P, Schultze-Mosgau S, Schlegel KA (2005) Stability of autogenous bone grafts after sinus lift procedures: a comparative study between anterior and posterior aspects of the iliac crest and an intraoral donor site. Oral Surg Oral Med Oral Pathol Oral Radiol Endod 100: 278-284.
Valentini P, Abensur D, Wenz B, Peetz M, Schenk R (2000) Sinus grafting with porous bone mineral (Bio-Oss) for implant placement: a 5-year study on 15 patients. Int $\mathrm{J}$ Periodontics Restorative Dent 20: 245-253.

Van de Wijngaert FP, Burger EH (1986) Demonstration of tartrate-resistant acid phosphatase in un-decalcified, glycolmethacrylate- embedded mouse bone: a possible marker for (pre)osteoclast identification. J Histochem Cytochem 34: 1317-1323.

Wallace SS, Froum SJ (2003) Effect of maxillary sinus augmentation on the survival of endosseous dental implants. A systematic review. Ann Periodontol 8: 328-343.

Wallace SS, Froum SJ, Cho SC, Elian N, Monteiro D, Kim BS, Tarnow DP (2005) Sinus augmentation utilizing anorganic bovine bone (Bio-Oss) with absorbable and nonabsorbable membranes placed over the lateral window: histomorphometric and clinical analyses. Int J Periodontics Restorative Dent 25: 551-559.

Zerbo IR, Zijderveld SA, de Boer A, Bronckers AL, de LG, ten Bruggenkate CM, Burger EH (2004) Histomorphometry of human sinus floor augmentation using a porous beta-tricalcium phosphate: a prospective study. Clin Oral Implants Res 15: 724-732.

Zijderveld SA, Zerbo IR, van den Bergh JP, Schulten EA, ten Bruggenkate CM (2005) Maxillary sinus floor augmentation using a beta-tricalcium phosphate (Cerasorb) alone compared to autogenous bone grafts. Int J Oral Maxillofac Implants 20: 432-440.

Zijderveld SA, Schulten EA, Aartman IH, ten Bruggenkate CM (2009) Long-term changes in graft height after maxillary sinus floor elevation with different grafting materials: radiographic evaluation with a minimum followup of 4.5 years. Clin Oral Implants Res 20: 691-700.

\section{Discussion with Reviewer}

Reviewer I: Please discuss whether the techniques used this study are limited to a specific surgical technique.

Authors: Our study is not about the advancement of a specific surgical technique. The study used an innovative multiparametric (histomorphometric and micro-CT) analysis in combination with a novel "onion-peeling" algorithm and a unique $1 \mathrm{~mm}$ ROI evaluation strategy, in order to perform detailed analyses on the effects of covering bone reconstruction surfaces with a collagenous membrane on the extent of new bone formation. However, we would like to stress that the MSFE procedure, and in particular our innovative approach, reaches far beyond the maxillary reconstruction per se., since it allows detailed and microscopic clinical evaluation of all types of novel therapies, such as stem cell-seeded bone substitutes for bone regeneration. Our novel approach thus represents a pivotal prerequisite for adequate evaluation of new innovative bone therapeutic modalities, and may set a new standard to measure safety and efficacy in clinical trials. Therefore, the results of our study are of interest to a broad area of scientific research fields and definitely not limited to maxillofacial surgery. 